\title{
Mapping indoor overheating and air pollution risk modification across Great Britain: A modelling study
}

Jonathon Taylor ${ }^{\mathrm{a}}$, Mike Davies ${ }^{\mathrm{a}}$, Anna Mavrogianni ${ }^{\mathrm{a}}$, Clive Shrubsole ${ }^{\mathrm{a}}$, Ian Hamilton ${ }^{\mathrm{b}}$, Payel Das ${ }^{\mathrm{a}}$, Benjamin Jones ${ }^{c}$, Eleni Oikonomou ${ }^{b}$, Phillip Biddulph ${ }^{b}$

Corresponding Author

Jonathon Taylor

UCL Institute for Environmental Design and Engineering,

Bartlett School of Environment, Energy and Resources,

Central House

14 Upper Woburn Plc

London

WC1H ONN

UK

${ }^{\mathrm{b}}$ Energy Institute, UCL, London

'Department of Architecture and Built Environment, University of Nottingham, Nottingham, UK

${ }^{1}$ Present Address: Rudolf Peierls Centre for Theoretical Physics, University of Oxford

\section{Abstract}

Housing has long been thought to play a significant role in population exposure to environmental hazards such as high temperatures and air pollution. However, there is sparse data describing how housing may modify heat and air pollution exposure such that housing's role in poor health and mortality from these hazards may be estimated. This paper describes the development of individualaddress level indoor overheating and air pollution risk modifiers for Great Britain, for use alongside historical weather, outdoor air pollution, population socio-economic data, and mortality data in a large-scale epidemiological investigation. A geographically-referenced housing stock database was developed using the Homes Energy Efficiency Database (HEED) and the English Housing Survey (EHS). Simulations of unique combinations of building, fabric, occupation, and environment were run using a modelling framework developed for EnergyPlus 8.0, estimating indoor temperature metrics, indoor/outdoor ratio of pollution from outdoor sources, and indoor air pollution from multiple indoor sources. Results were compiled, matched back to individual properties in HEED, and the results mapped using Geographical Information Systems (GIS). Results indicate urban areas had higher numbers of buildings prone to overheating, reduced levels indoor air pollution from outdoor sources, and higher air pollution from indoor sources relative to rural areas, driven largely by variations in building types. The results provide the first national-scale quantitative estimate of heat 
and indoor air pollution modification by dwellings, aggregated at levels suitable for inclusion in health analysis.

\section{Keywords}

Overheating; IAQ; Building Stock Modelling; Building Physics

\section{Introduction}

Evaluating health risks caused by exposure to high temperatures has increased as a research priority in Europe, in large part due to recent events such as the 2003 heatwave which caused approximately 2,000 excess deaths in the UK [1], and the projected increase in temperatures and frequencies of extreme temperature events caused by climate change [2]. Similarly, the health consequences of air pollution continue to be an important research area due to the significant healthcare burden; for example, the percentage of deaths attributable to particulate air pollution (PM) across England is estimated at 5.4\% [3]. Epidemiological studies, including [1,3], predict health consequences using outdoor temperatures and air pollution levels as estimates of exposure, and to date there has been comparatively little work relating indoor exposures to health outcomes. Buildings, and the manner in which they are constructed, will act as an important modifier of population exposure to environmental hazards such as heat and air pollution, particularly in the UK where the population is estimated to spend around $70 \%$ of its time inside their own homes [4]. Additionally, while epidemiological studies have accounted for the spatial variation of population vulnerability and outdoor environmental hazards in estimating risk, they have largely ignored how the variation in housing stock may influence exposure in the indoor environment.

\subsection{Indoor overheating}

In the UK, increased heat-related mortality has been observed in the elderly [5-7], those with preexisting health problems [5,8,9], and those living in care homes [10]. Consequently, with an aging population and increased risk of extreme temperature events under a changing climate, heat-related mortality is likely to pose a significant future challenge. The role of physical dwelling characteristics and indoor temperatures in heat-related mortality risk has been examined in France, which found elderly, vulnerable individuals living in top-floor flats and poorly-insulated houses were most at-risk [11], and in Chicago, which suggested that those living in buildings with fewer rooms and with flat roofs were at greater risk [12]. Living without air conditioning $(A / C)$ has also been linked to increased risk of heat-related mortality [13] in the US, although this is unlikely to be a major factor in the UK where $A / C$ in dwellings is estimated to be in only $3 \%$ of all housing [14]. For national studies, spatially-distributed climate effects have been accounted for. Armstrong et al [15] used linked postcode mortality data and regional temperature data to develop an association between the spatially distributed maximum outdoor temperature and relative risk of mortality. Postcode-level mortality and regional weather data was similarly used by Gasparrini et al [5] to examine the impact of heat on cause-specific mortality. District-level mortality and climate data has been used to estimate mortality effects of heat under current and future climate scenarios [16]. 
A number of monitoring [17-20] and modelling [21-25] studies support the conclusion that different types of UK dwellings have a range of overheating vulnerabilities, potentially acting as important modifiers of population heat exposure. Flats, particularly those on the top floor, bungalows, and more modern dwellings may be more prone to high indoor temperatures [18,21,22]. Energy-efficient modifications to dwellings, such as airtightening and internal solid-wall insulation, may increase dwelling vulnerability to overheating [21,22].

\subsection{Indoor air pollution}

As with temperature and climate, exposure to outdoor air pollution may vary spatially. In Sheffield, UK, epidemiological analyses have shown an excess risk of stroke mortality and hospital admission in areas with higher modelled air pollution levels [26]. At the national level, spatially-distributed monitored air pollution and health records identified a significant association between long-term exposure to particulate matter and $\mathrm{SO}_{2}$ concentrations and mortality [27]. Analysis of modelled air pollution and postcode-level health data found evidence of a link between long-term particulate matter and $\mathrm{NO}_{2}$ exposure on heart failure in England [28]. Epidemiological research has generally focused on outdoor air pollution, and there is less research examining health consequences from indoor air pollution in UK housing, although there is evidence that poorly ventilated dwellings may lead to increased asthma incidence [29].

The majority of studies on indoor air pollution in the UK have focused on modelling and monitoring approaches in order to estimate exposure concentrations. Monitoring of pollution from outdoor sources in UK dwellings include [30-35], but, at present, there is little empirical evidence to show differences in indoor concentrations across different building types despite known differences in ventilation performance. Building characteristics and ventilation appear to have an important influence on exposure to pollutants from indoor sources [36]. The role of buildings in indoor air pollution levels has been specifically examined in modelling studies. Dimitroulopoulou et al modelled $\mathrm{NO}_{2}, \mathrm{CO}, \mathrm{PM}_{10}$ and $\mathrm{PM}_{2.5}$ from both indoor and outdoor sources [37], demonstrating how low ventilation rates may increase exposure and the high relative importance of indoor sources. Indoor air quality modelling has been performed across sets of London [38] and English housing archetypes [39], showing how flats may have higher levels of pollution from indoor sources and lower levels from outdoor sources, relative to houses. Models of energy-efficient changes to the building fabric indicate reductions in permeability lead to an increase in indoor air pollution and decrease in outdoor air pollution in the indoor environment $[38,40]$. Indoor pollution is coupled to temperature due to the stack effect [41] and the need to increase ventilation to prevent overheating during summer.

\subsection{Housing modification of population exposure}

As housing may act as an important modifier in heat and air pollution exposure, the incorporation of housing stock data has been considered in a selection of exposure studies. The indoor/outdoor (I/O) ratios and absolute indoor concentrations of outdoor $\mathrm{PM}_{2.5}$ across the London housing stock was estimated using building physics models, a housing stock model, and maps of outdoor $\mathrm{PM}_{2.5}$ concentrations [42]; results showed the lower ventilation rates of flats in Central London helped offset high outdoor pollution levels. Chen et al. (2012) demonstrated a correlation between estimated exposure to indoor $\mathrm{PM}_{10}$ from outdoor sources in different US cities based on typical infiltration rates in local building stocks [43]. The population-wide health consequences arising from 
changes in indoor air quality following energy efficient adaptation in the English housing stock has been estimated by Hamilton et al [39] using a nationally-representative housing stock model.

Spatial variation in mortality risks from high indoor temperatures have been examined across London, accounting for population age, Urban Heat Island (UHI) impacts, with building physics models estimating indoor temperatures for individual dwellings [44]; results indicate that housing may be an important contributor to heat exposure. Principal components analysis has also been used to locate heat vulnerability populations in London due to UHI, housing, population age, population density, pre-existing health conditions, socio-economic status, and social isolation [45]. Other studies indicating housing as an important modifier of mortality risk has also been included in studies in the US using local air conditioning (A/C) prevalence [46], and with housing characteristics in Birmingham, UK [47] and Melbourne, Australia [48].

\subsection{Objectives}

While the above building modelling and monitoring studies have focused on examining overheating and air pollution differences between building types, between regionally-representative housing stocks, or across a city or region, there has not been any research to produce a national-level model of indoor heat and air pollution exposure, aggregated at a level that would enable comparison with postcode-level mortality data. Additionally, the above UK epidemiological studies have identified heat and air pollution as being hazards (factors which may adversely affect health); have established relationships between the exposure (the degree to which the population is exposed to the hazard) and mortality risk; and have investigated population vulnerability (the risk and protective factors of the exposed population). However, these relationships are derived from outdoor heat and pollution levels, and there has been little research to derive relationships with modelled indoor exposure using national spatially-varying mortality and housing stock data.

The objective of this work, therefore, is to develop spatially-varying estimates of housing-related modifiers of mortality risk due to heat and air pollution for Great Britain (GB). These risk modifiers will be used as estimates of more proximate risk factors (indoor temperature and indoor air pollution) from less proximate ones (outdoor temperature and air pollution) in future epidemiological analyses. To do this, a building stock database representative of the British housing stock was developed from a number of different data sources, and unique building variants identified. These variants were simulated for indoor overheating risk and indoor air pollution levels from both outdoor and indoor sources with EnergyPlus 8.0 [49], using the modelling framework previously described for outdoor air pollution [42], overheating [21,23,44,50], and coupled overheating and indoor and outdoor air pollution [22]. The simulation results were compiled, and the results mapped at postcode and Lower Super Output Area (LSOA)-level, a UK statistical boundary area that roughly corresponds to 500 households using Geographical Information Systems (GIS).

\section{Methods}

This section details the data sources, their integration into a building stock model, and the indoor temperature and air pollution modelling. An overview of the methods and the sections in which they 
are described can be seen in Figure 1.

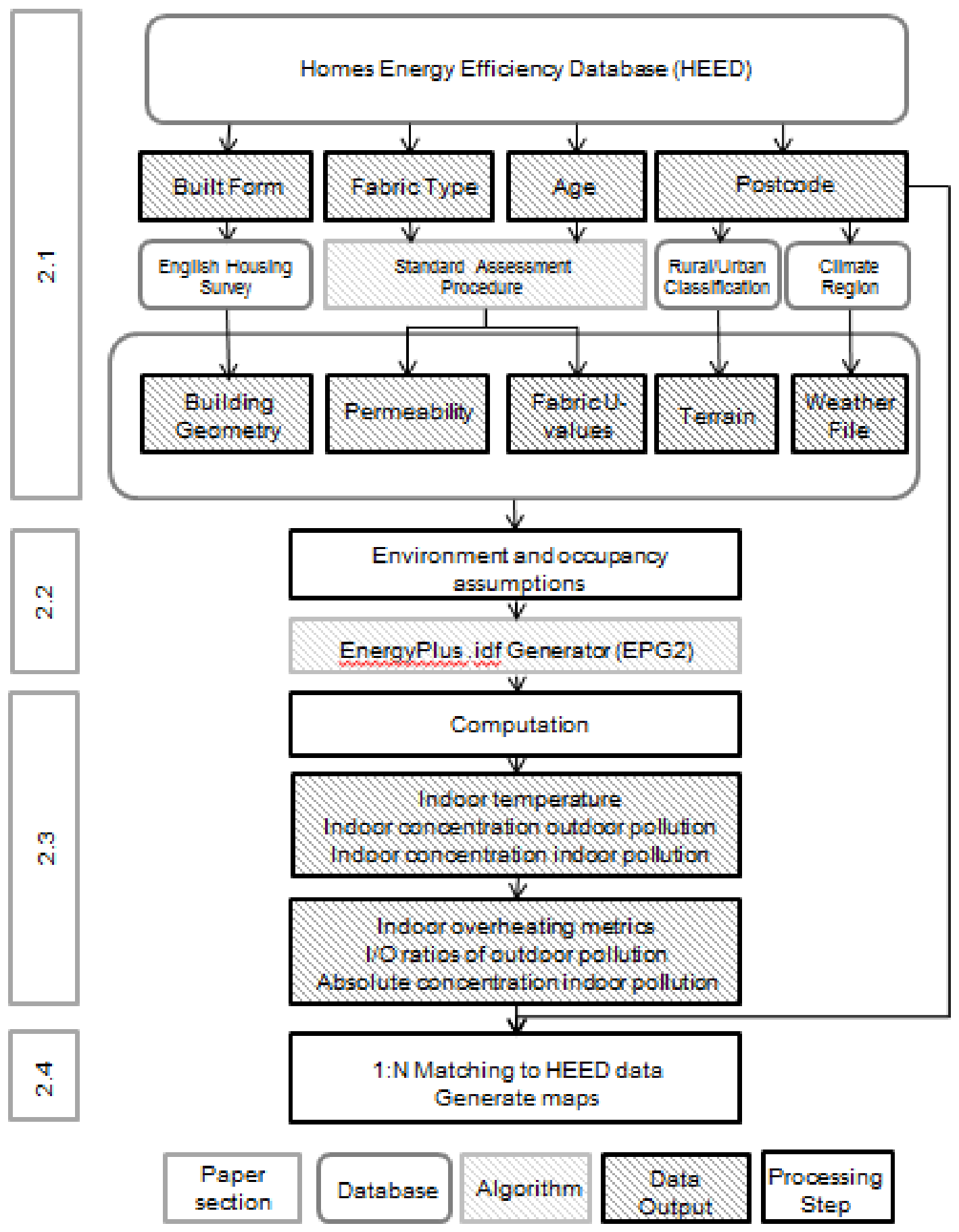

Figure 1. Project workflow. Further detail about the steps in the model development can be found in the different paper sections.

\subsection{Housing and environment data}

\subsubsection{Housing data}

Data on housing was derived from two housing databases:

- The 2010-2011 English Housing Survey (EHS) [51]: A cross-sectional survey representative of dwellings and households living therein with a focus on physical conditions, and includes details on energy efficiency in England; 
- The Homes Energy Efficiency Database (HEED) [52]: A database containing records of energy efficiency installations in the UK housing stock.

HEED was used as the basis of the AWESOME building stock model, as 1) it has postcode information that would enable the mapping of local housing modifications, while the EHS is locatable only by Government Office Regions (GOR), and 2) the age classifications are directly comparable to the classifications used in the UK Governments Standard Assessment Procedure (SAP) for Energy Rating in Dwellings [53], and 3) it offers comprehensive coverage of most energy efficiency interventions installed in the English housing stock between 2002 to 2012 [54]. While approximately 1 million dwellings within HEED had sufficient data to enable their overheating and indoor air pollution risks to be estimated, these represent only $4 \%$ of the estimated 25.8 million households in England, Scotland, and Wales estimated in the 2011 census [55]. Comparison of the number of dwellings in the HEED with census estimates of household numbers within LSOAs indicate that the coverage of dwellings with sufficiently detailed information for simulation in HEED was generally poor, ranging from $0-27 \%$, and with greater coverage in the North of England than in the South. At postcode-level, coverage ranged from 0 to an estimated 41 dwellings (mean of 1.83 in postcodes with housing data). The distribution of housing types with sufficient information to enable the modelling within the HEED database reflected previous studies of $\operatorname{HEED}[48,69]$, with detached and semi-detached dwellings overrepresented and flats under-represented when compared to the EHS (Table 1).

Table 1. Comparison of housing stocks with sufficient data for indoor overheating and air pollution modelling from the HEED-derived housing stock model, and the England-wide housing stock from the EHS.

\begin{tabular}{|l|r|r|}
\hline & \multicolumn{1}{|l|}{ HEED } & \multicolumn{1}{l|}{ EHS } \\
\hline End Terrace & 9.7 & 10.1 \\
\hline Detached & 24.7 & 17.0 \\
\hline Bungalow & 8.2 & 8.9 \\
\hline $\begin{array}{l}\text { Semi } \\
\text { Detached }\end{array}$ & 34.4 & 26.2 \\
\hline Mid Terrace & 22.6 & 18.3 \\
\hline Flats & 0.4 & 19.6 \\
\hline
\end{tabular}

HEED informed the built form, age, fabric characteristics, and location of the dwelling. SAP tables were used to estimate $U$-values for walls, windows, roofs, and floors for each entry in the HEED database, based on the recorded age of the property, the fabric type, and the level of insulation. Different $\mathrm{U}$-values were used according to whether the dwelling was in England and Wales or Scotland. All windows that were post-2002 double glazed were assumed to have trickle vents installed, as per building regulations at the time [56]. Building fabric materials data was taken from the WUFI database [57]; fabric U-values were modified by adjusting materials and thicknesses whilst maintaining construction type (e.g. solid wall vs cavity wall). Trickle vents were sized according to building regulations [56]. Specific ventilation behaviour is discussed in Section 2.2. 
The built form geometry was derived from the EHS database, as described in the paper by Oikonomou et al [58], and included End terraces, Mid terraces, Semi-detached, Detached, Bungalows, Converted flats, Low-ride Purpose-built flats, and High-rise Purpose-built flats. These built forms were then assigned to each entry in the HEED database based on the built form of each record. For flats, geometries were provided for ground, middle, and top-floor flats. It was assumed that dwellings in Scotland and Wales had similar geometries to those in the EHS. Dwellings older than 1929 were modelled with a suspended floor [47], and with vents to the subfloor; all others were modelled with solid floors. All dwellings with lofts were modelled with vents, sized as per building regulations [56].

Building airtightness is modelled by applying a permeability, or an air leakage rate per hour at 50Pa, to the building fabric. This permeability was estimated for each entry in the EHS using the SAP methodology, as the HEED database did not have sufficient information to be able to accurately estimate permeability. The average permeability for each building in the EHS was calculated for each combination of age, built form, and fabric types, and the resultant permeabilities applied to the AWESOME building stock model. The permeability of Scottish and Welsh housing was calculated in the same manner, under the assumption that the permeability of their housing was similar to the estimated permeability distributions of English homes.

Shading from adjoining buildings was applied based on information provided in the HEED database (for example, if the dwelling was classified as semi-detached it had a single party wall, if midterraced it had two). Flats were modelled with two or three adjacent flats, depending on the geometry of the buildings (i.e. no corner flats were modelled). Shading dwellings were modelled as mirrors of the modelled dwelling, with an adiabatic party wall.

\subsubsection{Environment data}

The location information provided for each property in HEED was used to locate the dwellings in terms of climate and terrain. The Office for National Statistics (ONS) 2011 rural/urban classification for small-area geographies for England and Wales [59] and Scottish Urban Rural Classifications [60] were used to classify dwellings as rural, urban, or city based on their LSOA or Scottish DataZone (DZ). In order to reduce the number of simulations, dwellings were assigned to three climate regions where the relative ranking of dwellings in terms of overheating metrics differs significantly; London, Southern and Central England (as represented by Plymouth) and Northern England and Scotland (as represented by Edinburgh) [50]. Two types of weather file, Design Summer Year (DSY), developed to represent a 'hot' summer for overheating modelling, and Test Reference Year (TRY), developed to represent an 'average' climate, were obtained for each location from CIBSE [61]. Static outdoor pollution levels were modelled, with outdoor-sourced indoor pollution levels used to estimate an I/O ratio during post-processing which may account for temporally or spatially varying outdoor pollution levels (Section 2.3.1).

Approximately 1 million dwellings in the HEED database had sufficient dwelling information to enable the indoor temperature and air pollution to be modelled. Where there was sufficient building information, unique combinations of building variables were selected and all combinations of dwellings where there were more than one example in the GB stock were selected to be modelled (approximately $97.5 \%$ of the 1 million dwellings). Buildings were modelled at four orientations (North, West, South, and East). 


\subsection{Building physics model}

Building physics models were run for buildings representative of the derived building stock using EnergyPlus 8.0, following the modelling framework developed for overheating $[21,23,44,50]$, outdoor air pollution $[22,38,42]$, indoor air pollution $[22,38]$, and coupled air pollution and temperature [22]. The methods and assumptions used in model development are briefly described below. A python-based in-house tool, EPG2, capable of rapidly generating a large number of EnergyPlus .idf files, was used to produce the simulation files.

\subsubsection{Overheating}

Overheating was modelled for each HEED entry with a unique combination of factors which influence overheating, including: geometry, fabric types, permeability, location, terrain, and with two different occupancy patterns (a family of five and two pensioners) and at four orientations (North, East, South, West). This resulted in a total of 41,200 unique simulations.

Occupancy schedules determine both internal gain patterns and period of exposure. Both internal gains and occupancy patterns were taken from Oikonomou et al [62]. The occupancy patterns, modelled after a family of five (two parents and three children) or two pensioners determined the internal gains and the room of exposure to indoor temperatures during certain times of the day; these two occupancy patterns were selected based on their ability to cause significant changes in the relative overheating risk of dwellings [23]. For more information on the occupancy schedules and internal gains, refer to $[21,62]$.

Heating was modelled to a $20^{\circ} \mathrm{C}$ setpoint during occupied hours [21,62]; while the actual set point is likely to vary significantly across dwellings, it was assumed to have little impact on overheating or indoor air pollution . As in previous studies $[19,20,35,53,56,57]$, window-opening was modelled to occur above a $25^{\circ} \mathrm{C}$ threshold in all rooms during the day, and above $23^{\circ} \mathrm{C}$ in the bedroom at night; if the outdoor temperature was above the indoor temperature, then windows did not open.

Overheating simulations were run using the DSY weather files, from May $1^{\text {st }}$ to August $30^{\text {th }}$. Indoor temperature in the main bedroom and living room was calculated at 10 minute intervals and output alongside outdoor temperature for each hour of the simulation period.

\subsubsection{Infiltration of outdoor air pollution}

The infiltration of outdoor pollution into the indoor environment was modelled for each of the HEED entries that had a unique combination of factors that impact infiltration [42]: geometry, permeability, and window type (and therefore trickle vent presence). Different locations, terrains, the presence/absence of extract fans, and the two different occupancy patterns were also modelled. Building ventilation was modelled using the permeability of the building envelope, trickle vents where present, temperature-dependent window opening, and extract fans located in the kitchens and bathrooms, sized according to building regulation requirements [56]. Where present, extract fans were modelled to run during cooking or showering; if absent, windows were opened during these activities instead. Occupant behaviours and internal gains were modelled as in overheating.

Pollutants modelled included $\mathrm{PM}_{2.5}, \mathrm{PM}_{10}, \mathrm{SO}_{2}, \mathrm{O}_{3}, \mathrm{NO}, \mathrm{NO}_{2}$, and $\mathrm{CO}$. The pollutant deposition rates or velocities can be seen in Table 2. For simplification, pollutant ingress into dwellings was modelled without penetration factors, which represent the fraction of pollution lost due to deposition in the 
cracks as it enters the building. Pollutant deposition rates or velocities and penetration factors typically have large uncertainties associated with them, and pollutant transport models are sensitive to the parameters modelled $[40,63]$. The sensitivity of the model employed here to penetration factor and deposition rate has been quantified in previous papers $[42,63]$.

Table 2. The deposition rates and velocities of the modelled pollutants.

\begin{tabular}{|l|l|l|l|}
\hline Pollutant & Deposition Rate $\left(\mathrm{h}^{-1}\right)$ & $\begin{array}{l}\text { Deposition Velocity } \\
\left(\mathrm{mh}^{-1}\right)\end{array}$ & Reference \\
\hline $\mathrm{PM}_{2.5}$ & 0.39 & & {$[64]$} \\
\hline $\mathrm{PM}_{10}$ & 0.65 & & {$[64]$} \\
\hline $\mathrm{O}_{3}$ & & 1.30 & {$[65]$} \\
\hline $\mathrm{SO}_{2}$ & 5.04 & {$[66]$} \\
\hline $\mathrm{NO}_{2}$ & & {$[67]$} \\
\hline $\mathrm{NO}$ & 0.87 & & {$[65]$} \\
\hline $\mathrm{CO}$ & 0 & & {$[65]$} \\
\hline
\end{tabular}

Pollutant infiltration simulations were run using the TRY weather files for each location for the full year, with the concentrations inside the main bedroom, kitchen, and living room calculated at 5 minute intervals and the results output hourly. The total number of models run for pollution infiltration was 23,604 .

\subsubsection{Indoor air pollution sources}

As with pollution from outdoor sources, pollution from indoor sources was modelled for each complete HEED entry with a unique combination of geometry, permeability, window type (and therefore trickle vent presence), location, terrain, two different occupancy patterns, and the presence/absence of extract fans. Modelled pollutant sources included those from cooking $\left(\mathrm{CO}, \mathrm{NO}_{2}\right.$, $\left.\mathrm{PM}_{10}, \mathrm{PM}_{2.5}\right)$, showering $\left(\mathrm{PM}_{2.5}\right)$, fireplaces $\left(\mathrm{PM}_{2.5}\right)$, and smoking $\left(\mathrm{NO}_{2}, \mathrm{CO}, \mathrm{PM}_{10}, \mathrm{PM}_{2.5}\right)$; their emission rates can be seen in Table 3. As with deposition rates, pollutant emission rates are highly uncertain, and model sensitivity to this parameter has been explored previously [40,63]. Emission rates were assumed to be the same for all dwellings, ignoring potential differences in emission rates due to the size of the dwelling and occupancy numbers; the large uncertainty in emission rates means that results should be used to evaluate variations and trends between buildings and location rather than absolute concentration estimates. The emission schedules (Table 4) were taken from the work of Shrubsole et al [40], which are either assumed or based on ONS household survey data. Deposition rates and velocities for the pollutants were the same as in Table 2. The same window-opening behaviour, occupancy behaviours, and internal gains were modelled as above.

Indoor-source pollutant simulations were run using the TRY weather files for the full year, with the concentrations inside the main bedroom, kitchen, and living room calculated 12 times an hour and the results output hourly. A total of 38,090 additional simulations were run for indoor pollution from indoor sources.

Table 3. Pollutant emission rates for indoor activities.

\begin{tabular}{|l|l|r|l|}
\hline & Pollutant & $\begin{array}{r}\text { Emission } \\
\text { rate } \\
(\mathrm{mg} / \mathrm{min})\end{array}$ & Reference \\
\hline Gas Cooking & $\mathrm{NO}_{2}$ & 3.1 & {$[29]$} \\
\hline
\end{tabular}




\begin{tabular}{|l|l|r|l|}
\hline Gas Cooking & $\mathrm{PM}_{2.5}$ & 1.6 & {$[29]$} \\
\hline Fireplace & $\mathrm{PM}_{2.5}$ & 0.2 & {$[63]$} \\
\hline Shower & $\mathrm{PM}_{2.5}$ & 0.04 & {$[64]$} \\
\hline Cooking & $\mathrm{CO}$ & 25 & {$[29]$} \\
\hline Cooking & $\mathrm{PM}_{10}$ & 4.1 & {$[29]$} \\
\hline Smoking & $\mathrm{NO}_{2}$ & 0.015 & {$[29]$} \\
\hline Smoking & $\mathrm{CO}$ & 7.2 & {$[29]$} \\
\hline Smoking & $\mathrm{PM}_{10}$ & 1.5 & {$[29]$} \\
\hline Smoking & $\mathrm{PM}_{2.5}$ & 0.9 & {$[29]$} \\
\hline
\end{tabular}

Table 4. Indoor pollutant emission schedule, from Shrubsole et al [34].

\begin{tabular}{|c|c|c|}
\hline Activity & Location & Schedule \\
\hline Cooking & Kitchen & $\begin{array}{l}07: 45-08: 00 \\
12: 00-12: 30 * \\
19: 00-19: 30\end{array}$ \\
\hline \multirow[t]{2}{*}{ Smoking } & Kitchen & $\begin{array}{l}8: 00-8: 05 \\
9: 00-9: 05 \\
\end{array}$ \\
\hline & Living Room & $\begin{array}{l}10: 00-10: 05^{*} \\
11: 00-11: 05^{*} \\
12: 00-12: 05^{*} \\
19: 00-19: 05 \\
20: 00-20: 05 \\
21: 00-21: 05 \\
22: 00-22: 05\end{array}$ \\
\hline
\end{tabular}

*refer to pensioners of families during weekends only

\subsection{Simulation and collation}

Simulations were run on remote servers (two Windows Servers, both with 6 cores), taking advantage of multiple processors to run the models. In addition, the Amazon Cloud [68] was used to rapidly run a large number of simulations. Indoor operative temperatures and air pollution levels were output hourly.

Data collation was performed using a SAS [69] script which ran through the simulation results, calculating overheating and indoor air pollution metrics (described below) for each dwelling. The results were averaged across orientations and mapped back to the HEED database based on the building characteristics. As there was no information on building occupants for the individual buildings in the HEED database, both family and pensioner occupancy results were matched to each HEED dwelling. Indoor pollution estimates were weighted according to the percent of working kitchen or bathroom extract fans for buildings of each age/built form/GOR combination, obtained from the EHS.

\subsubsection{Metrics}

There is no consensus on how to best assess overheating inside dwellings [70], and a number of metrics can give statistically different performance rankings despite dwellings being modelled under the same conditions [23]. As the primary objective of this work was to produce markers of risk modification that could be used in epidemiological analysis rather than indicators of thermal 
discomfort, metrics which could be incorporated into existing health models were calculated from hourly data. These metrics, and their advantages and disadvantages can be seen in Table 5

Table5. Exposure metrics for overheating and indoor air pollution.

\begin{tabular}{|c|c|c|c|c|}
\hline & Metric & Definition & Advantage & Disadvantage \\
\hline \multirow{10}{*}{ 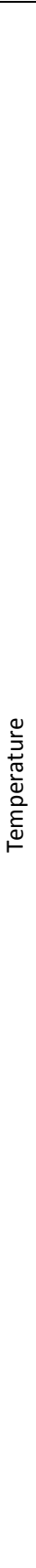 } & MMDT & $\begin{array}{l}\text { Summertime Mean Maximum } \\
\text { Daytime living room } \\
\text { Temperature }\end{array}$ & \multirow{2}{*}{$\begin{array}{l}\text { Indicator of average indoor } \\
\text { temperature }\end{array}$} & \multirow{2}{*}{$\begin{array}{l}\text { Does not capture extremes or } \\
\text { frequency of high temperatures }\end{array}$} \\
\hline & MMNT & $\begin{array}{l}\text { Summertime Mean Night time } \\
\text { Minimum bedroom Temperature }\end{array}$ & & \\
\hline & NL25 & $\begin{array}{l}\text { Number of hours above } 25^{\circ} \mathrm{C} \text { in } \\
\text { the living room }\end{array}$ & \multirow{2}{*}{$\begin{array}{l}\text { Indicator of high temperature } \\
\text { frequency }\end{array}$} & \multirow{2}{*}{$\begin{array}{l}\text { Does not capture temperature } \\
\text { when exceeded; not compatible } \\
\text { with existing heat-mortality } \\
\text { relationships in England and } \\
\text { Wales [15]. }\end{array}$} \\
\hline & NL28 & $\begin{array}{l}\text { Number of hours above } 28^{\circ} \mathrm{C} \text { in } \\
\text { the living room }\end{array}$ & & \\
\hline & MDTTX & $\begin{array}{l}\text { Mean Daytime living room } \\
\text { temperature when regional } \\
\text { mortality outdoor Temperature } \\
\text { Thresholds are eXceeded }\end{array}$ & $\begin{array}{l}\text { Compatible with existing heat- } \\
\text { mortality relationships in England } \\
\text { and Wales [15]. Frequency } \\
\text { scalable by outdoor weather data }\end{array}$ & \multirow{2}{*}{$\begin{array}{l}\text { Does not capture extreme indoor } \\
\text { temperatures or impact of } \\
\text { temperatures on previous days. } \\
\text { Does not account for difference in } \\
\text { dwelling relative overheating } \\
\text { performance under 'warm' and } \\
\text { 'hot' conditions. }\end{array}$} \\
\hline & MDTTXdiff & $\begin{array}{l}\text { Mean difference between } \\
\text { Daytime living room temperature } \\
\text { and outdoor temperature when } \\
\text { regional mortality outdoor } \\
\text { Temperature Thresholds are } \\
\text { eXceeded }\end{array}$ & $\begin{array}{l}\text { Compatible with existing heat- } \\
\text { mortality relationships in England } \\
\text { and Wales [15]. Local outdoor } \\
\text { temperature data can be used to } \\
\text { scale and calculate frequency. }\end{array}$ & \\
\hline & MDL_93_97.5 & $\begin{array}{l}\text { Mean difference between } \\
\text { Daytime Average living room } \\
\text { indoor and outdoor temperature } \\
\text { when the two-day rolling mean } \\
\text { outdoor temperature is between } \\
\text { the } 93^{\text {rd }} \text { percentile and the } 97.5^{\text {th }} \\
\text { percentile of historical regional } \\
\text { temperatures }\end{array}$ & \multirow{2}{*}{$\begin{array}{l}\text { Compatible with existing heat- } \\
\text { mortality relationships in England } \\
\text { and Wales [15]. Local outdoor } \\
\text { temperature data can be used to } \\
\text { scale and calculate frequency. } \\
\text { Captures indoor temperatures } \\
\text { when outdoor temperatures are } \\
\text { 'warm' }\end{array}$} & \multirow{2}{*}{$\begin{array}{l}\text { Does not capture extreme indoor } \\
\text { temperatures }\end{array}$} \\
\hline & MNB_93_97.5 & $\begin{array}{l}\text { Mean difference between Night } \\
\text { time Average Bedroom indoor } \\
\text { and outdoor temperature when } \\
\text { the two-day rolling mean } \\
\text { outdoor temperature is between } \\
\text { the } 93^{\text {rd }} \text { percentile and the } 97.5^{\text {th }} \\
\text { percentile of historical regional } \\
\text { temperatures }\end{array}$ & & \\
\hline & MDL_97.5 & $\begin{array}{l}\text { Mean difference between } \\
\text { Daytime Average living room } \\
\text { indoor and outdoor temperature } \\
\text { when the two-day rolling mean } \\
\text { outdoor temperature exceeds } \\
\text { the } 97.5 \text { percentile and of } \\
\text { historical regional temperatures }\end{array}$ & \multirow{2}{*}{$\begin{array}{l}\text { Compatible with existing heat- } \\
\text { mortality relationships in England } \\
\text { and Wales [15]. Local outdoor } \\
\text { temperature data can be used to } \\
\text { scale and calculate frequency. } \\
\text { Captures indoor temperatures } \\
\text { when outdoor temperatures are } \\
\text { 'hot'. }\end{array}$} & \multirow{2}{*}{$\begin{array}{l}\text { Does not capture extreme indoor } \\
\text { temperatures }\end{array}$} \\
\hline & MNB_97.5 & $\begin{array}{l}\text { Mean difference between Night } \\
\text { time Average Bedroom indoor } \\
\text { and outdoor temperature when } \\
\text { the two-day rolling mean } \\
\text { outdoor temperature exceeds } \\
\text { the } 97.5 \text { percentile and of } \\
\text { historical regional temperatures }\end{array}$ & & \\
\hline \multirow[b]{2}{*}{$\frac{\text { 을 }}{\stackrel{ }{\bar{D}}}$} & I/O ratio & $\begin{array}{l}\text { Ratio of indoor pollution from } \\
\text { outdoor sources only to outdoor } \\
\text { pollution. Calculated based on } \\
\text { the room occupancy schedule, } \\
\text { averaged for each building } \\
\text { occupant. }\end{array}$ & $\begin{array}{l}\text { Can be multiplied by local outdoor } \\
\text { pollution levels to obtain absolute } \\
\text { indoor concentrations of outdoor } \\
\text { origin. }\end{array}$ & $\begin{array}{l}\text { Has not been aggregated at } \\
\text { different temporal scales to } \\
\text { capture daily or seasonal } \\
\text { behavioural differences. I/O } \\
\text { ratios conventionally include } \\
\text { indoor sources, however these } \\
\text { are excluded in order to estimate } \\
\text { pollutant infiltration only. }\end{array}$ \\
\hline & $\begin{array}{l}\text { Absolute } \\
\text { concentration of } \\
\text { indoor pollutions } \\
\text { from indoor } \\
\text { sources }\left(\mu \mathrm{g} / \mathrm{m}^{3}\right)\end{array}$ & $\begin{array}{l}\text { Exposure calculated based on the } \\
\text { room occupancy schedule, } \\
\text { averaged for each building } \\
\text { occupant. }\end{array}$ & $\begin{array}{l}\text { Provides indicator of relative } \\
\text { performance of building variants } \\
\text { on indoor pollution exposure. }\end{array}$ & $\begin{array}{l}\text { Does not capture peak emission } \\
\text { exposures. Does not capture } \\
\text { exposure of individual generating } \\
\text { pollution }\end{array}$ \\
\hline
\end{tabular}




\subsection{Mapping}

The average of each metric was then calculated for postcodes and LSOA/DZ in the HEED database in SAS and the data exported to ArcGIS [71] to be mapped. The number of addresses with known data within each unit area was also calculated, allowing for future epidemiological analysis to account for data coverage.

\section{Results}

The results presented here examine trends across the British housing stock due to building type and environment. A more detailed analysis of differences due to built form, fabric type, permeability, the presence of vents, and model sensitivity can be seen in the papers describing model development $[21-23,38,42,44,50]$.

\subsection{Indoor overheating}

Overheating results reflect those from previous papers using this model, as well as overheating studies of the GB housing stock [18], with bungalows and top-floor flats most vulnerable to high indoor temperatures; an increase in overheating associated with dwelling airtightness; and poor roof insulation increasing overheating inside dwellings with living rooms or bedrooms on the top floors (Figure 2). As expected, dwellings modelled under the London climate were observed to be hottest, while those in Edinburgh the coolest; ranges also reflect the variability of the regional housing stocks. Pensioners were seen to have a greater exposure to high temperatures than the family, due to their presence inside the home during the hottest periods of the day.

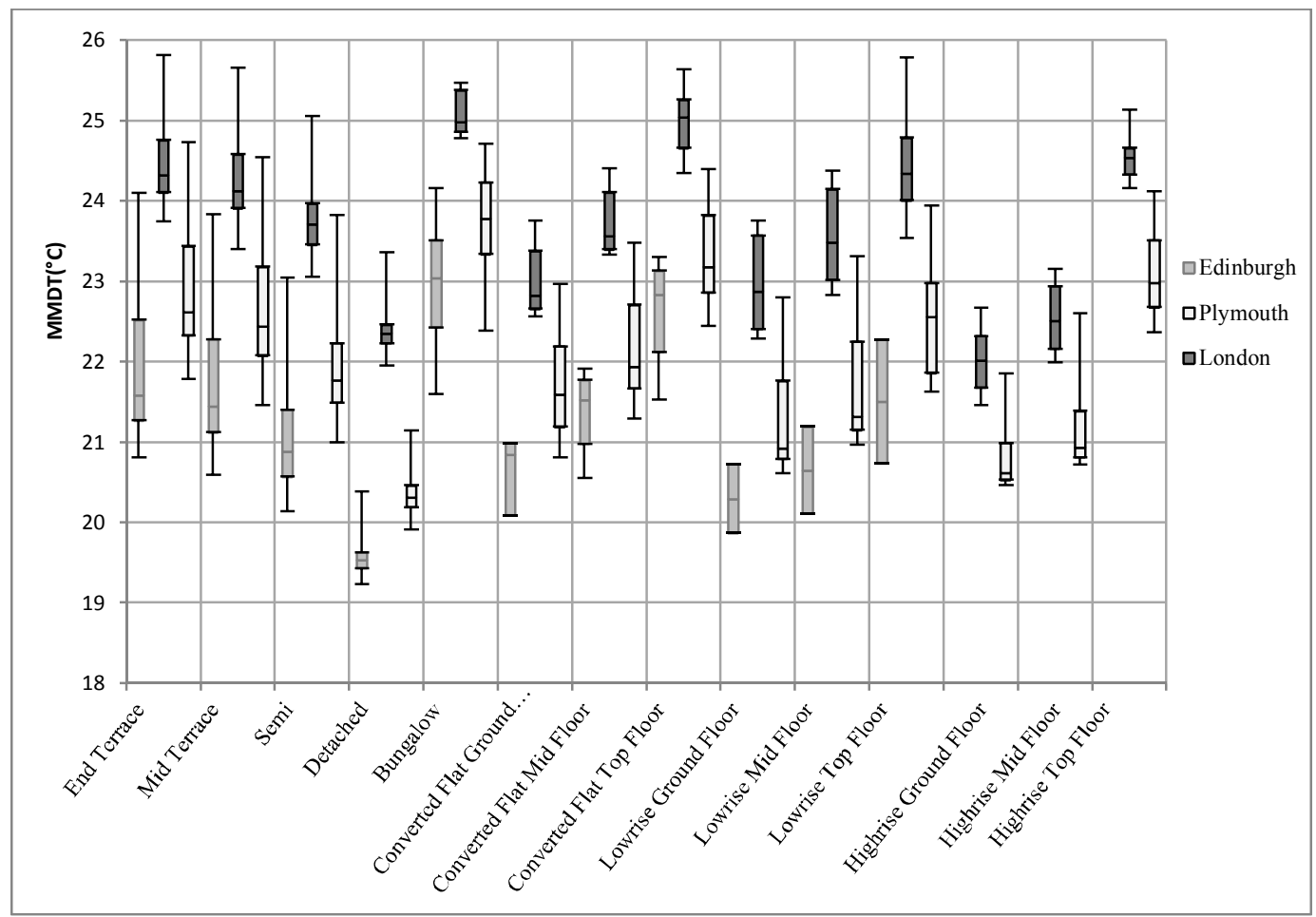

Figure2. Indoor temperature, in MMDT, for pensioners in the different built forms under the different climates. The ranges account for variations in building fabric characteristics observed within each climate region. 
Comparisons between overheating metrics across postcodes show a range of linear correlations (Pearson) between the metrics, meaning that spatial trends may differ depending on metric.

Generally, there was a good correlation between metrics when the metric was in the same unit (e.g. ${ }^{\circ} \mathrm{C}$ or hours above threshold) or time of day (Table 6), while correlations were lower across different units or when comparing moderate to high temperature scenarios. Britain-wide trends in heat risk modification for families and pensioners (MMDT and MMNT) can be seen in Figure 3. In this figure, LSOA-average indoor overheating metrics (MMDT and MMNT) are normalised as +/- standard deviations from the climate-region mean in order to visualise the local variations due to housing rather than absolute differences due to climate. A higher number of vulnerable dwellings can be seen in urban areas, likely due to the prevalence of flats and shaded dwellings. Pockets of vulnerable dwellings can also be seen in non-urban settings when there are large numbers of bungalows present. While presenting summary statistics at the LSOA-level allows for spatial trends to be identified, it implies a greater coverage of housing data than is actually present. Compiled results at the postcode level can be seen in the Appendix.

Table 6. Pearson correlation coefficients for postcode overheating metrics, normalised per climate region.

\begin{tabular}{|c|c|c|c|c|c|c|c|c|c|c|}
\hline & $\begin{array}{r}\text { MMD } \\
T\end{array}$ & $\begin{array}{r}\text { MMN } \\
T\end{array}$ & $\begin{array}{r}\mathrm{NL2} \\
5\end{array}$ & $\begin{array}{r}\text { NL2 } \\
8\end{array}$ & $\begin{array}{r}\text { MDTT } \\
x\end{array}$ & $\begin{array}{r}\text { MDTTXdi } \\
\text { ff }\end{array}$ & MDL_93_97 & MNB_93_97 & $\begin{array}{r}\text { MDL_97. } \\
5\end{array}$ & MNB_97. \\
\hline MMDT & 1.00 & 0.82 & 0.95 & 0.69 & 0.96 & 0.96 & 0.94 & 0.64 & 0.93 & 0.48 \\
\hline MMNT & 0.82 & 1.00 & 0.79 & 0.29 & 0.78 & 0.78 & 0.88 & 0.87 & 0.75 & 0.65 \\
\hline NL25 & 0.95 & 0.79 & 1.00 & 0.71 & 0.95 & 0.95 & 0.92 & 0.63 & 0.92 & 0.49 \\
\hline NL28 & 0.69 & 0.29 & 0.71 & 1.00 & 0.71 & 0.71 & 0.52 & 0.14 & 0.70 & 0.04 \\
\hline MDTTX & 0.96 & 0.78 & 0.95 & 0.71 & 1.00 & 1.00 & 0.95 & 0.67 & 0.98 & 0.58 \\
\hline MDTTXdiff & 0.96 & 0.78 & 0.95 & 0.71 & 1.00 & 1.00 & 0.95 & 0.66 & 0.98 & 0.57 \\
\hline $\begin{array}{r}\text { MDL_93_97. } \\
5\end{array}$ & 0.94 & 0.88 & 0.92 & 0.52 & 0.95 & 0.95 & 1.00 & 0.80 & 0.94 & 0.69 \\
\hline $\begin{array}{r}\text { MNB_93_97 } \\
.5 \\
\end{array}$ & 0.64 & 0.87 & 0.63 & 0.14 & 0.67 & 0.66 & 0.80 & 1.00 & 0.68 & 0.85 \\
\hline MDL_97.5 & 0.93 & 0.75 & 0.92 & 0.70 & 0.98 & 0.98 & 0.94 & 0.68 & 1.00 & 0.61 \\
\hline MNB_97.5 & 0.48 & 0.65 & 0.49 & 0.04 & 0.58 & 0.57 & 0.69 & 0.85 & 0.61 & 1.00 \\
\hline
\end{tabular}




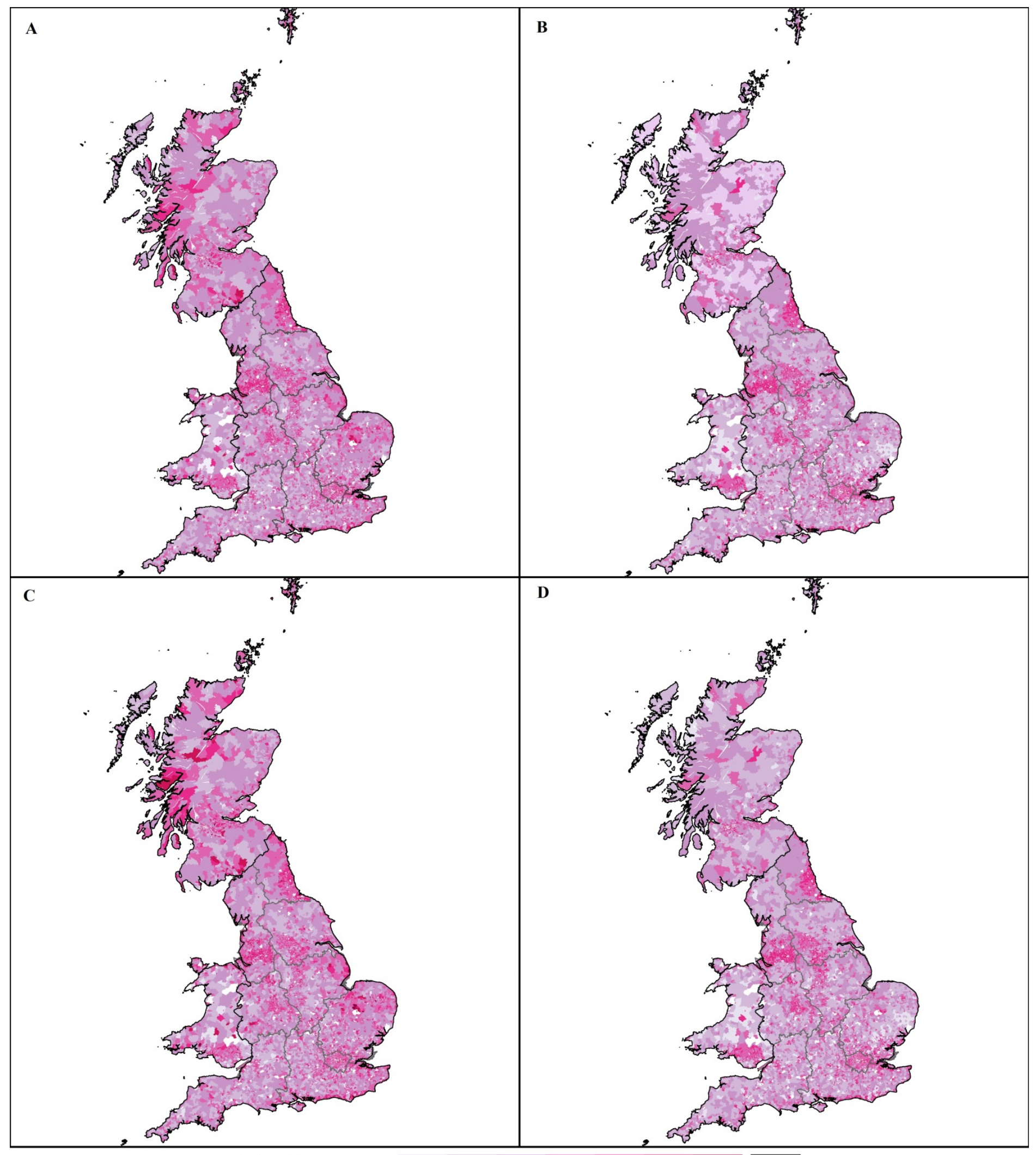

Overheating Risk

Temperature normalised per climate region

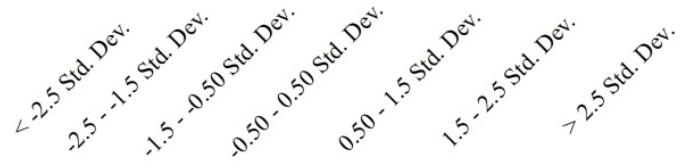


Figure3. LSOA (England and Wales) and DZ (Scotland)-level mean dwelling overheating estimates, including A) MMDT, pensioners, B) MMNT, pensioners, C) MMDT, family, and D) MMNT, family. Due to absolute temperature differences across climate regions, values are normalised for each region as +/- from the regional-mean in order to demonstrate the role of housing rather than climate on exposure.

\subsection{Indoor pollution from outdloor sources}

1/O ratio, or the fraction of outdoor-sourced Indoor pollution relative to outdoor levels, were found to be lower in flats and mid-terraced dwellings, and higher in bungalows and detached dwellings (Figure 4). This supports previous modelling of pollutant infiltration into UK dwellings, which found that the permeability and exposed external surface area and internal volume of the dwelling led to differences in $1 / O$ ratio between dwelling types [42]. I/O ratios of building variants were found to be higher in rural locations, likely due to more prevalent leaky dwellings and greater wind exposure due to shading and terrain, while the $\mathrm{I} / \mathrm{O}$ ratios in city locations were the lowest due to more airtight dwellings and lower wind exposure. Pollutants with higher deposition rates had lower I/O ratios than those with low deposition rates; $\mathrm{CO}$ and NO which were modelled without a deposition rate had concentrations equivalent to the outdoor levels, and an I/O ratio of 1.

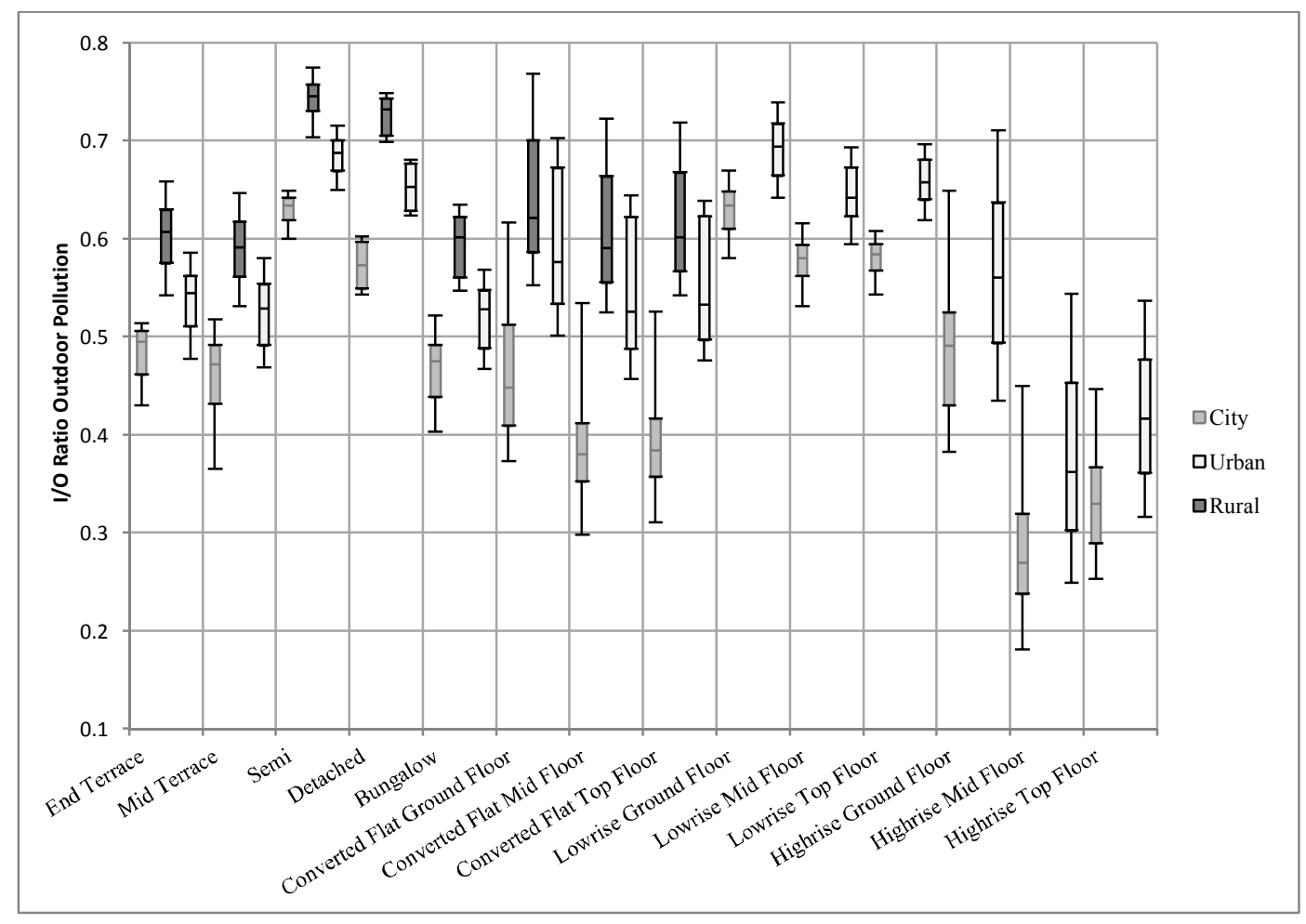

Figure 4. I/O ratios for $\mathrm{PM}_{2.5}$ in different dwelling types according to rural/urban/ and city locations.

The estimated I/O ratios across GB at LSOA-level can be seen in Figure 5 for $\mathrm{PM}_{2.5}$. Higher I/O ratios were found in rural locations due to greater numbers of detached dwellings and a greater exposure to wind, increasing wind pressures and pollutant infiltration. While outdoor pollutant levels were not used at this stage in the project, outdoor pollutant levels are typically higher in urban areas, in contrast to the modelled I/O ratios. There was a strong spatial correlation in postcode and LSOAaverage $\mathrm{I} / \mathrm{O}$ ratios for pollutants with deposition due to the use of the same set of underlying housing models with a single varying input (deposition rate/velocity). A map of postcode-level estimates can also be seen in the Appendix. 


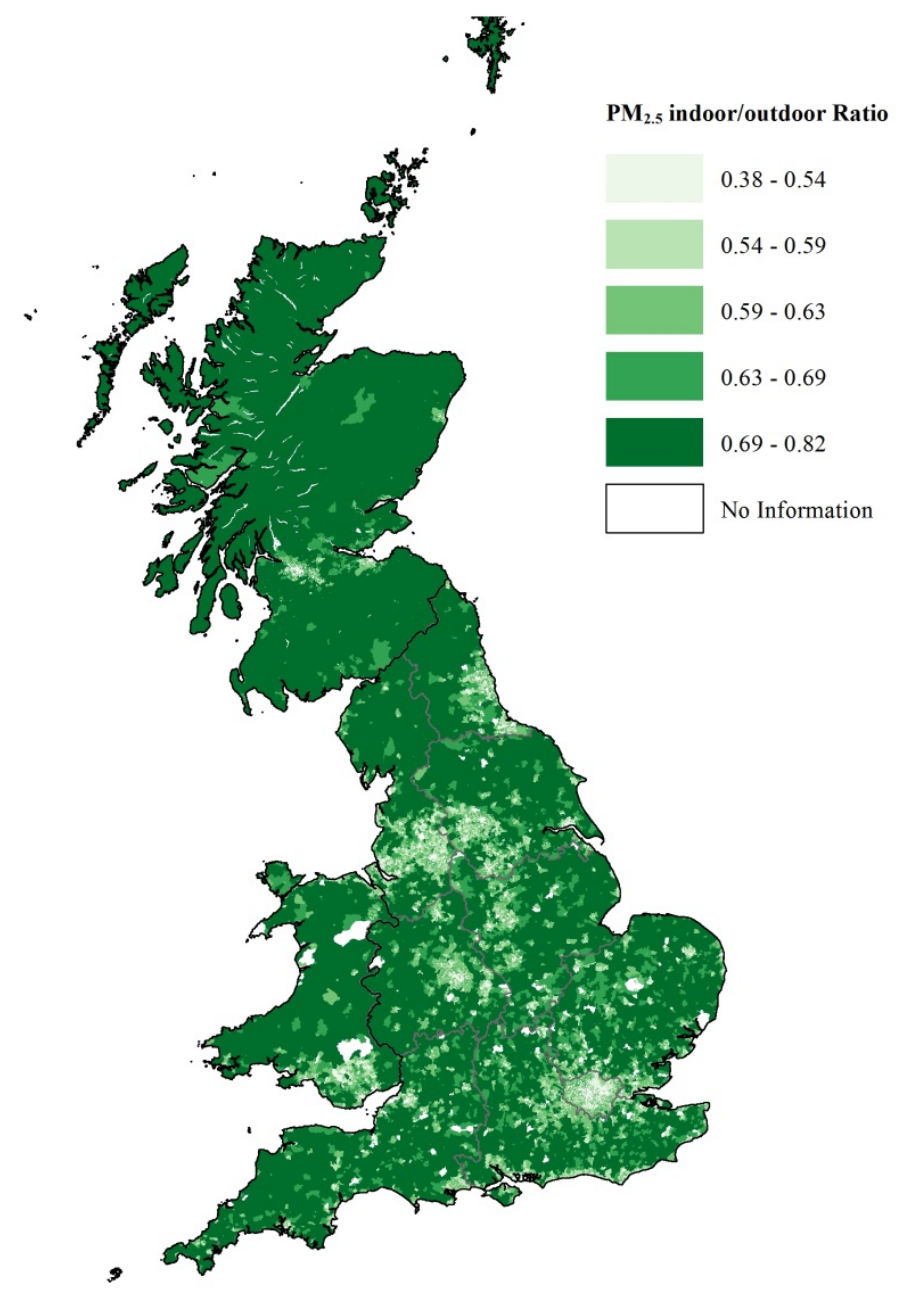

Figure 5. Estimated LSOA and DZ-average $\mathrm{I} / \mathrm{O}$ ratio for $\mathrm{PM}_{2.5}$. Other pollutants with deposition showed similar spatial trends.

\subsection{Indoor pollution from indoor sources}

Levels of pollution from indoor sources varied between dwellings depending on the activity and the individuals exposed. Cooking produced the highest levels of $\mathrm{PM}_{2.5}$ exposure for an individual, for example, whereas smoking was highest when exposure was averaged for all building occupants based on their location within the dwelling. Building-to-building differences were generally the opposite of those observed for outdoor pollution, with dwellings with lower air change rates exhibiting higher indoor concentrations. However it is acknowledged that there is a great level of uncertainty in emission rates and occupant behaviours, which means that results should be indicative of general trends between buildings rather than absolute indoor pollution levels. In cases where extract fans were modelled, such as during cooking, differences between buildings were less clear, however the general spatial trend of pollutants from all indoor sources was similar across the country. Figure 6 illustrates the LSOA-level variation of the levels of $\mathrm{PM}_{2.5}$ from cooking and smoking, with results adjusted according to regional differences in working kitchen extract fans; the equivalent post-code level map can be seen in the appendix. 


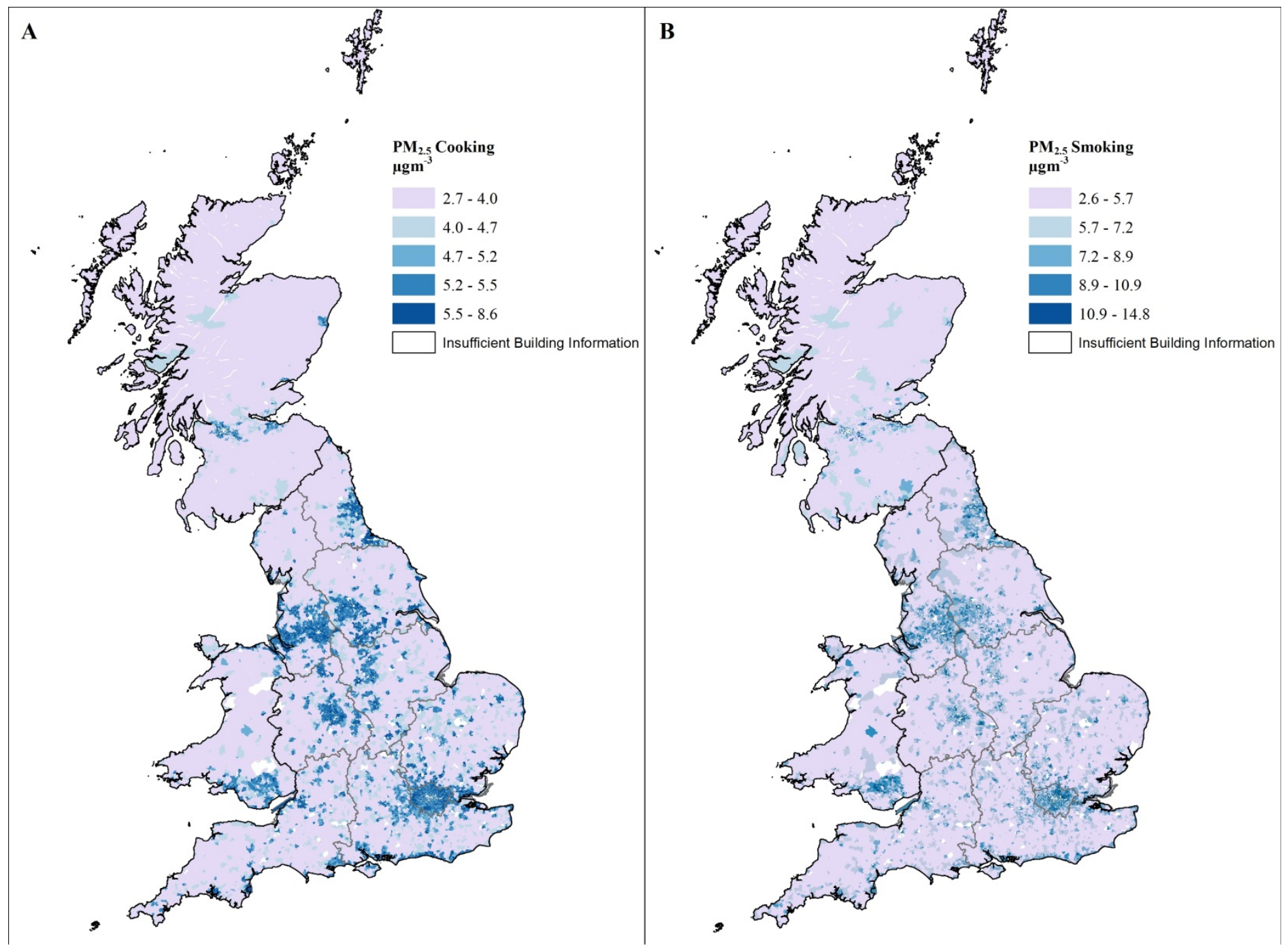

Figure 6. Estimated LSOA and DZ-average indoor concentration of $\mathrm{PM}_{2.5}$ for cooking (A) and smoking (B).

\section{Discussion}

\subsection{Housing stock}

The HEED database was the largest database available at the time of the study that contained precise building and location data, and so was used as the basis of the AWESOME housing stock models. HEED has shown a good agreement when compared to the EHS [72], however there are fewer flats and more semi-detached dwellings than in the EHS; fewer privately-rented and more socially-rented dwellings; and fewer homes in the South of England than in the EHS. It is suggested that this reflects greater government and energy-supplier investment in deprived or low-income areas [54]. Because there exists a database to record energy-efficient retrofits across the country, it is likely that a bias exists towards housing that has some kind or refurbishment, and so may underestimate the numbers of 'as-built' dwellings. Due to the relatively poor coverage of the HEED 
database, there is significant uncertainty in postcode-level estimates. Results should therefore be considered within the context of national trends. At the time of the model development, HEED provided the best platform for AWESOME, however the Home Analytics Database [73], a new dataset which is able to provide probabilistic estimates of building fabric characteristics for more than $95 \%$ of the addresses in GB, may offer future opportunities to extend the model coverage.

Due to a lack of spatially-linked information in the building stock databases, certain dwellings which may be extremely vulnerable to overheating have not been modelled, for example dwellings with loft conversions and these with internal solid wall insulation. Additionally, adaptations such as $A / C$ have not been modelled due to the relative rarity in the GB housing stock. The potentially significant role of occupants in indoor temperature [62] and air pollution levels has also not been investigated beyond the two occupant scenarios detailed above. Local shading from neighbouring buildings has been accounted for based on building type and terrain, but shading from other sources such as vegetation has not been modelled due to a lack of building-specific overshadowing data. By focusing work on existing building variants and climates, the model is unable to project future changes which are unmodelled. Further work is ongoing, using the foundations of this model to develop a metamodel from EnergyPlus simulations that may be adaptable to changes in occupant behaviours, climate, and building stock.

\subsection{Overheating}

The results of the indoor overheating modelling support previous studies [74], as well as those used as a basis for the model. Bungalows and top-floor flats were predicted to be most vulnerable to overheating, along with more modern airtight terraced dwellings. Dwelling overheating vulnerability was sensitive to the metric used to describe the temperature, and future analysis of the results alongside mortality data may help to identify the metrics most strongly associated with mortality risk. While there is a dearth of studies investigating the levels of indoor air pollution across different types of housing, indoor air pollution results support previous work $[22,38,42]$ with flats generally having lower I/O ratios than bungalows, detached, or semi-detached dwellings, and with dwelling airtightness reducing pollutant infiltration. As in previous studies [22,38], indoor pollution from indoor sources was seen to be the inverse of that from outdoor sources, with higher concentrations in flats, more airtight buildings, and those with smaller room volumes, although the presence of extract fan ventilation minimised much of these differences.

LSOA and postcode-average indoor overheating risks were mapped normalised relative to the climate-region mean, as a map of absolute indoor temperature metrics would be dominated to the relatively hot climate of London, and the variation due to buildings would be less apparent. Following climate-specific normalisation, there was greater overheating vulnerability in urban locations due to the predominance of flats and terraced buildings relative to rural areas. The described work did not take into account local temperature variations due to Urban Heat Islands (UHIs), although these are likely to amplify the differences between urban and rural locations further.

\subsection{Indoor air pollution}

Pollutant infiltration was strongly affected by wind exposure, which, when combined with the greater frequency of bungalows and detached dwellings meant that higher levels of indoor pollution from outdoor sources were found in rural areas. This variation is likely in contrast to the spatial 
variation in outdoor pollution levels, particularly those produced from traffic which are likely to be higher in urban areas. Conversely, indoor pollution levels from indoor sources were higher in urban areas due to the reduced wind exposure, and the predominance of smaller, more airtight dwellings like modern flats.

Outdoor pollutant levels are known to vary both over the course of a day and seasonally, while building $\mathrm{I} / \mathrm{O}$ ratio may also vary due to differences in seasonal window-opening behaviour and outdoor weather conditions [42]. A year-average $1 / O$ ratio is therefore a simplification of the actual infiltration of outdoor pollutants, however given that absolute indoor concentrations have not yet been calculated as this part of this work a year-average $\mathrm{I} / \mathrm{O}$ ratio is appropriate. For indoor pollutant modelling, a single set of building fabrics was modelled; fabrics will influence overheating risk, and therefore may cause slight variation in indoor pollutant levels due to changes in air buoyancy and the amount of window-opening during the summer, but these differences have been found to be relatively small when averaged over a year [22]. There is significant uncertainty in both the emission and deposition of the modelled pollutants. It is likely that emissions from certain activities (for example cooking or smoking) will vary across building types due to dwelling size and the number of potential occupants. The modelled results represent the potential role of the building in pollution exposure, but are not representative of the true variations in indoor concentrations likely seen across the British housing stock.

\subsection{Further research}

The outputs from this research will be used in an epidemiological study, where the relationship between these indoor overheating and air pollution metrics and mortality will be examined, alongside historical weather data, outdoor air pollution, and socioeconomic data. This future work will help to establish the role of buildings on exposure to these hazards, and help to identify overheating metrics which may best associate with mortality risk due indoor heat exposure. Additionally, further work is ongoing to extend the modelling framework to allow for the prediction of overheating risks under future climate scenarios, with building stock adaptations, as well as accounting for more local variations in temperature caused by, for example, urban heat islands using a metamodeling approach.

\section{Conclusions}

To our knowledge, the results represent the first mapped estimates of national dwelling heat and indoor air quality modification. Postcode-level estimates of housing modification of heat and air pollution mortality have been developed in order to estimate a more proximate indoor exposure from an outdoor exposure, and to enable the role of housing on mortality from these hazards to be better understood. Results predict greater housing modification of heat exposure in urban areas relative to rural areas due to the prevalence of dwellings such as flats and terraces which can be vulnerable to overheating. Indoor air pollution is also predicted to vary according to dwelling and location, with lower levels of outdoor pollution infiltration predicted for urban areas due to higher number of more modern, airtight flats and terraced dwellings. Conversely, dwellings in urban areas are predicted to have higher levels of indoor air pollution from indoor sources relative to rural areas, due to the lower background ventilation rates caused by the dominant building types. Further work, using the output metrics as modifiers of mortality risk, will help better understand the role of housing on heat and air pollution mortality. 


\section{Acknowledgements}

This research was carried out with funding from the Natural Environment Research Council as part of the AWESOME Project (Air pollution and Weather-related health impacts: methodological study based on spatio-temporally disaggregated multipollutant models for present day and future) (NE/I007938/1).

\section{References}

[1] Johnson H, Kovats R, McGregor G. The impact of the 2003 heat wave on daily mortality in England and Wales and the use of rapid weekly mortality estimates. Eurosurveillance 2005;10:558.

[2] Murphy J, Sexton D, Jenkins G, Boorman P, Booth B, Brown K, et al. UKCP09 Climate change projections. Exeter: 2009.

[3] PHE. Public Health Outcomes Framework Tool. Public Health England: 2012.

[4] ONS. United Kingdom Time Use Survey. Office for National Statistics, London: 2005.

[5] Gasparrini A, Armstrong B, Kovats S, Wilkinson P. The effect of high temperatures on causespecific mortality in England and Wales. Occupational and Environmental Medicine 2012;69:56-61.

[6] Hajat S, Kovats RS, Lachowycz K. Heat-related and cold-related deaths in England and Wales: who is at risk? Occupational and Environmental Medicine 2007;64:93-100.

[7] Johnson H, Kovats R. The impact of the 2003 heat wave on mortality and hospital admissions in England. Health Statistics Quarterly 2005;25:6-11.

[8] Page L, Hajat S, Kovats R, Howard L. Temperature-related deaths in people with psychosis, dementia and substance misuse. The British Journal of Psychiatry 2012;200:485-90.

[9] Kovats R, Hajat S, Wilkinson P. Contrasting patterns of mortality and hospital admissions during hot weather and heat waves in Greater London, UK. Occupational and Environmental Medicine 2004;61:893-8.

[10] Kovats RS, Johnson H, Griffith C. Mortality in southern England during the 2003 heat wave by place of death. Health Statistics Quarterly / Office for National Statistics 2006:6-8.

[11] Vandentorren S, Bretin P, Zeghnoun A, Mandereau-Bruno L, Croisier A, Cochet C, et al. August 2003 heat wave in France: risk factors for death of elderly people living at home. European Journal of Public Health 2006;16:583-91.

[12] Chan N, Stacey M, Smith A, Ebi K, Wilson T. An empirical mechanistic framework for heatrelated illness. Climate Research 2001;16:133-43.

[13] O'Neill MS, Zanobetti A, Schwartz J. Disparities by race in heat-related mortality in four US cities: the role of air conditioning prevalence. Journal of Urban Health : Bulletin of the New York Academy of Medicine 2005;82:191-7.

[14] BRE. Energy Follow-Up Survey 2011: Report 9: Domestic appliances, cooking \& cooling equipment. Building Research Establishment, London, UK:2013.

[15] Armstrong BG, Chalabi Z, Fenn B, Hajat S, Kovats S, Milojevic A, et al. Association of mortality with high temperatures in a temperate climate: England and Wales. Journal of Epidemiology and Community Health 2011;65:340-5.

[16] Bennett J, Blangiardo M, Fecht D. Vulnerability to the mortality effects of warm temperature in the districts of England and Wales. Nature Climate Change 2014;4:269-273. 
[17] Lomas K, Kane T. Summertime temperatures in 282 UK homes: thermal comfort and overheating risk. Proceedings of 7th Windsor Conference: The changing context of comfort in an unpredictable world, 2012.

[18] Beizaee A, Lomas KJ, Firth SK. National survey of summertime temperatures and overheating risk in English homes. Building and Environment 2013;65:1-17.

[19] Mavrogianni A, Davies M, Wilkinson P, Pathan A. London Housing and Climate Change: Impact on Comfort and Health - Preliminary Results of a Summer Overheating Study. Open House International 2010;35:49-59.

[20] Mavrogianni A, Taylor J, Davies M, Thoua C, Kolm-Murray J. Urban social housing resilience to excess summer heat. Building Research \& Information 2015;43:316-33.

[21] Mavrogianni A, Wilkinson P, Davies M, Biddulph P, Oikonomou E. Building characteristics as determinants of propensity to high indoor summer temperatures in London dwellings. Building and Environment 2012;55:117-30.

[22] Taylor J, Mavrogianni A, Davies M, Das P, Shrubsole C, Biddulph P, et al. Understanding and mitigating overheating and indoor PM2.5 risks using coupled temperature and indoor air quality models. Building Services Engineering Research and Technology 2015;36:275-289.

[23] Mavrogianni A, Davies M, Taylor J, Chalabi Z, Biddulph P, Oikonomou E, et al. The impact of occupancy patterns, occupant-controlled ventilation and shading on indoor overheating risk in domestic environments. Building and Environment 2013;78:183-98.

[24] Porritt SM, Cropper PC, Shao L, Goodier Cl. Ranking of interventions to reduce dwelling overheating during heat waves. Energy and Buildings 2012;55:16-27.

[25] Peacock AD, Jenkins DP, Kane D. Investigating the potential of overheating in UK dwellings as a consequence of extant climate change. Energy Policy 2010;38:3277-88.

[26] Maheswaran R, Haining R, Brindley P. Outdoor air pollution and stroke in Sheffield, United Kingdom a small-area level geographical study. Stroke 2005;36:239-243.

[27] Elliott $P$, Shaddick $G$, Wakefield J. Long-term associations of outdoor air pollution with mortality in Great Britain. Thorax 2007;62:1088-1094.

[28] Atkinson R, Carey I, Kent A. Long-term exposure to outdoor air pollution and incidence of cardiovascular diseases. Epidemiology 2013;24:44-53.

[29] Sharpe RA, Thornton CR, Nikolaou V, Osborne NJ. Higher energy efficient homes are associated with increased risk of doctor diagnosed asthma in a UK subpopulation. Environment International 2015;75:234-44.

[30] Jones N., Thornton C., Mark D, Harrison R. Indoor/outdoor relationships of particulate matter in domestic homes with roadside, urban and rural locations. Atmospheric Environment 2000;34:2603-12.

[31] Lai HK, Bayer-Oglesby L, Colvile R, Götschi T, Jantunen MJ, Künzli N, et al. Determinants of indoor air concentrations of PM2.5, black smoke and NO2 in six European cities (EXPOLIS study). Atmospheric Environment 2006;40:1299-313.

[32] Hoek G, Kos G, Harrison R, de Hartog J, Meliefste K, ten Brink H, et al. Indoor-outdoor relationships of particle number and mass in four European cities. Atmospheric Environment 2008;42:156-69.

[33] Wheeler A.J., Williams I., Beaumont R.A., Hamilton R.S. Characterisation of Particulate Matter Sampled during a Study of Children's Personal Exposure to Airborne Particulate Matter in a UK Urban Environment. Environmental Monitoring and Assessment 2000;65:6977. 
[34] Wigzell E, Kendall M, Nieuwenhuijsen MJ. The spatial and temporal variation of particulate matter within the home. Journal of Exposure Analysis and Environmental Epidemiology 10:307-14.

[35] Nasir ZA, Colbeck I. Particulate pollution in different housing types in a UK suburban location. The Science of the Total Environment 2013;445-446:165-76.

[36] Davies M, Ucci M, McCarthy M, Oreszczyn T, Ridley I, Mumovic D, et al. A review of evidence linking ventilation rates in dwellings and respiratory health---a focus onhealth dust mites and mould. International Journal of Ventilation 2004;3:155-68.

[37] Dimitroulopoulou C, Ashmore MR, Hill MTR, Byrne MA, Kinnersley R. INDAIR: A probabilistic model of indoor air pollution in UK homes. Atmospheric Environment 2006;40:6362-79.

[38] Shrubsole C, Taylor J, Das P, Hamilton I, Davies M. Impacts of energy efficiency retrofitting measures on indoor PM2.5 concentrations across different income groups in England: a modelling study. Advances in Building Energy Research 2015 (ahead-of-print):1-5.

[39] Hamilton I, Milner J, Chalabi Z, Das P, Jones B, Shrubsole C, et al. Health effects of home energy efficiency interventions in England: a modelling study. BMJ Open 2015;5:e007298.

[40] Shrubsole C, Ridley I, Biddulph P, Milner J, Vardoulakis S, Ucci M, et al. Indoor PM2.5 exposure in London's domestic stock: Modelling current and future exposures following energy efficient refurbishment. Atmospheric Environment 2012;62:336-43.

[41] Taylor J, Shrubsole C, Biddulph P, Jones B, Das P, Davies M. Simulation of pollution transport in buildings: the importance of taking into account dynamic thermal effects. Building Services Engineering Research and Technology 2014;35:682-690.

[42] Taylor J, Shrubsole C, Davies M, Biddulph P, Das P, Hamilton I, et al. The modifying effect of the building envelope on population exposure to PM2.5. Indoor Air 2014;24:639-51.

[43] Chen C, Zhao B, Weschler CJ. Indoor Exposure to Outdoor PM10 : Assessing Its Influence on the Relationship Between PM10 and Short-term Mortality in U.S. Cities. Epidemiology 2012;23:870-8.

[44] Taylor J., Wilkinson P, Davies M, Armstrong B, Chalabi Z, Mavrogianni A, et al. Mapping the effects of Urban Heat Island, housing, and age on excess heat-related mortality in London. Urban Climate 2015;14:517-528.

[45] Wolf T, McGregor G. The development of a heat wave vulnerability index for London, United Kingdom. Weather and Climate Extremes 2013;1:59-68.

[46] Reid CE, O'Neill MS, Gronlund CJ, Brines SJ, Brown DG, Diez-Roux A V, et al. Mapping community determinants of heat vulnerability. Environmental Health Perspectives 2009;117:1730-6.

[47] Tomlinson CJ, Chapman L, Thornes JE, Baker CJ. Including the urban heat island in spatial heat health risk assessment strategies: a case study for Birmingham, UK. International Journal of Health Geographics 2011;10:42.

[48] Loughnan M, Nicholls N, Tapper N. Mapping heat health risks in urban areas. International Journal of Population Research 2012.

[49] US-DOE. EnergyPlus V8 United States Department of Energy, Washington, DC 2013.

[50] Taylor J, Davies M, Mavrogianni A, Chalabi Z, Biddulph P, Oikonomou E, et al. The relative importance of input weather data for indoor overheating risk assessment in dwellings.

Building and Environment 2014;76:81-91.

[51] DCLG. English Housing Survey 2010-2011. Department for Communities and Local Government, London, UK, 2011. 
[52] EST. Homes Energy Efficiency Database (HEED). Energy Saving Trust, London, 2013.

[53] BRE. The Government's Standard Assessment Procedure for Energy Rating of Dwellings. Watford, UK: Building Research Establishment; 2009.

[54] Hamilton IGI, Shipworth D, Summerfield AJ, Steadman P, Oreszczyn T, Lowe R. Uptake of energy efficiency interventions in English dwellings. Building Research \& Information 2014;42:255-75.

[55] ONS. 2011 Census: Census Output Area Statistics (England and Wales). Office for National Statistics, London, 2011.

[56] HM Government. Approved Document F. London, UK: 2010.

[57] IBP. WUFI-2D, PC-Program for calculating the coupled heat and moisture transfer in building components. Fraunhofer-Institut for Building Physics, Holzkirchen. 2007.

[58] Oikonomou E, Mavrogianni A, Raslan R, Taylor J, Oreszczyn T, Davies M. English Archetypes: Developing a domestic model for building performance calculations 2015.

[59] Office for National Statistics. 2011 rural/urban classification for small-area geographies. London 2011.

[60] Scottish Government. Urban Rural Classification 2011-2012 2012.

[61] CIBSE. Current CIBSE TRY/DSY hourly weather data set - 14 sites. Chartered Institute of Building Services Engineers, London 2013.

[62] Oikonomou E, Davies M, Mavrogianni A, Biddulph P, Wilkinson P, Kolokotroni M. Modelling the relative importance of the urban heat island and the thermal quality of dwellings for overheating in London. Building and Environment 2012;57:223-38.

[63] Das P, Shrubsole C, Jones B, Hamilton I, Chalabi Z, Davies M, et al. Using probabilistic sampling-based sensitivity analyses for indoor air quality modelling. Building and Environment 2014;78:171-82.

[64] Ozkaynak H, Xue J, Spengler J. Personal exposure to airborne particles and metals: results from the Particle TEAM study in Riverside, California. Journal of Exposure Analysis and Environmental Epidemiology 1996;6:57-78.

[65] Nazaroff WW, Cass GR. Mathematical modeling of chemically reactive pollutants in indoor air. Environmental Science \& Technology 1986;20:924-34.

[66] Grøntoft T, Raychaudhuri MR. Compilation of tables of surface deposition velocities for O3, $\mathrm{NO} 2$ and $\mathrm{SO} 2$ to a range of indoor surfaces. Atmospheric Environment 2004;38:533-44.

[67] Emmerich S, Persily A. Multizone modeling of three residential indoor air quality control options. Gaithersburg, MD: National Institute of Standards and Technology, Building and Fire Research Laboratory; 1996.

[68] Amazon. Elastic Compute Cloud (EC2). Accessed January 2014.

[69] SI. SAS software: version 9.3. SAS Institute, Cary, NC, USA 2013.

[70] Zero Carbon Hub. Defining Overheating: Evidence Review. London, UK: 2015.

[71] ESRI. ArcGIS 10.1. Environmental Systems Research Institute, Redlands, USA 2013.

[72] Hamilton IG, Steadman PJ, Bruhns H, Summerfield AJ, Lowe R. Energy efficiency in the British housing stock: Energy demand and the Homes Energy Efficiency Database. Energy Policy 2013;60:462-80.

[73] EST. Home Analytics. Energy Saving Trust, London 2015.

[74] DCLG. Investigation into Overheating in Homes. Department for Communities and Local 
Government, London, UK: 2012.

Appendix 


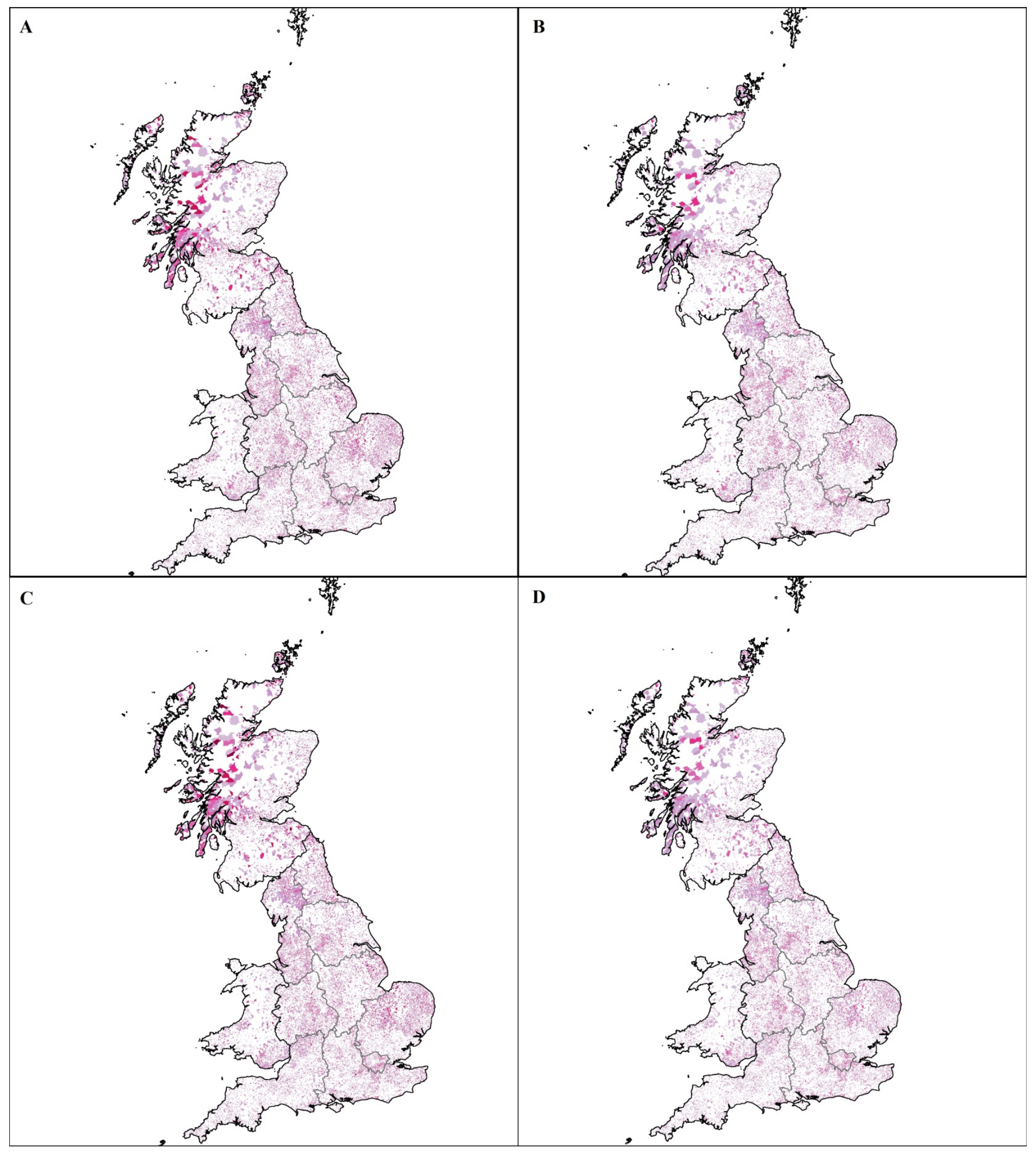

Temperature normalised per climate region

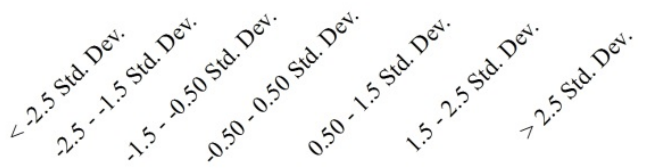


Figure A1. Postcode-level mean dwelling overheating estimates, including A) MMDT, pensioners, B) MMNT, pensioners, C) MMDT, family, and D) MMNT, family. Due to absolute temperature differences across climate regions, values are normalised for each region as +/- from the regional-mean in order to demonstrate the role of housing rather than climate on exposure.

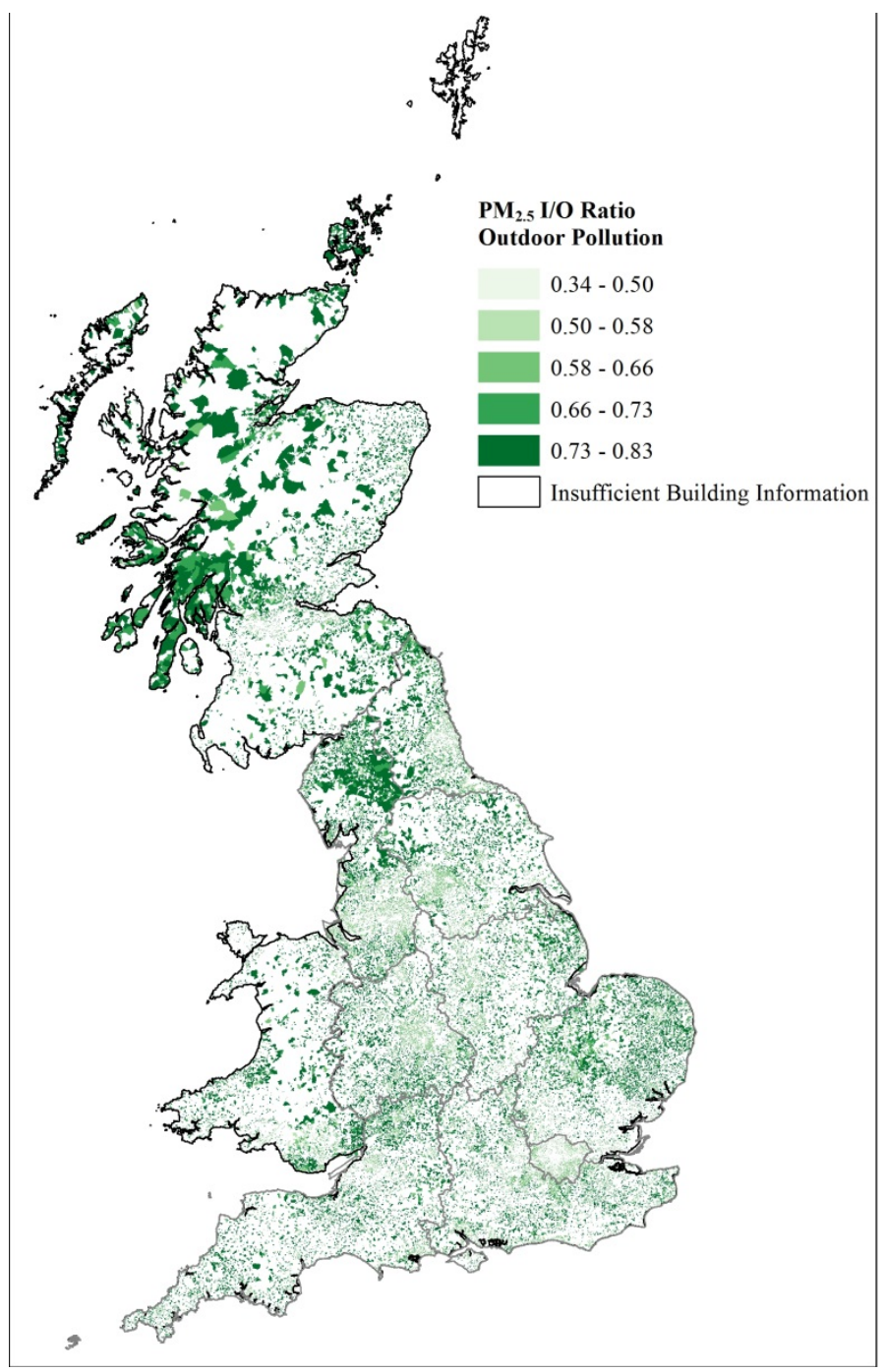

Figure A2. Estimated postcode-average I/O ratio for $\mathrm{PM}_{2.5}$. 


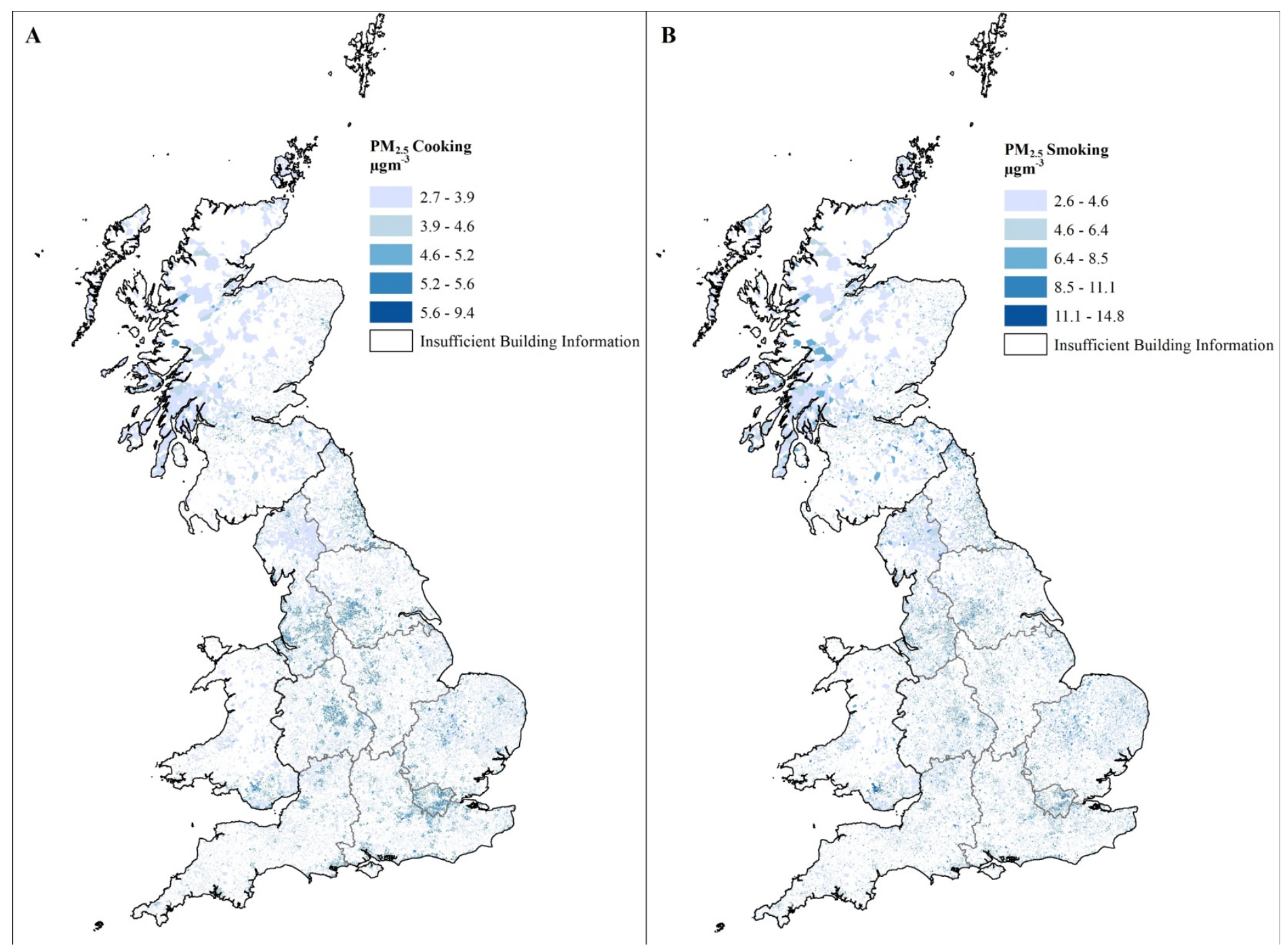

Figure A3. Estimated postcode-average indoor concentration of $\mathrm{PM}_{2.5}$ for cooking (A) and smoking (B). 